\author{
Key Words: Electrolysis \\ Hydrogen \\ Temperature \\ Membrane \\ Catalyst \\ Membrane Electrode Assembly
}

\title{
Component Development Needs for the Hybrid Sulfur Electrolyzer
}

\author{
H. R. Colon-Mercado \\ M. C. Elvington \\ D. T. Hobbs
}

May 2008

\section{We Put Science To Work ${ }^{\mathrm{m}}$}




\section{DISCLAIMER}

This report was prepared by Washington Savannah River Company (WSRC) for the United States Department of Energy under Contract No. DE-AC09-96SR18500 and is an account of work performed under that contract. Neither the United States Department of Energy, nor WSRC, nor any of their employees makes any warranty, expresses or implied, assumes any legal liability or responsibility for accuracy, completeness, or usefulness, of any information, apparatus, or product or process disclosed herein or represents that its use will not infringe privately owned rights. Reference herein to any specific commercial product, process, or service by trademark, name, manufacturer or otherwise does not necessarily constitute or imply endorsement, recommendation, or favoring of same by WSRC or by the United States Government or any agency thereof. The views and opinions of the authors expressed herein do not necessarily state or reflect those of the United States Government or any agency thereof. 


\section{CONTENTS}

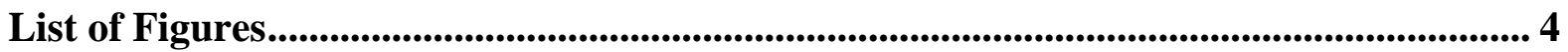

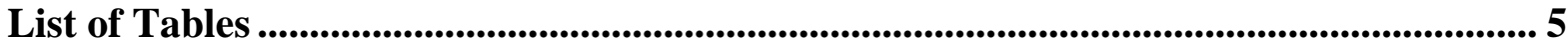

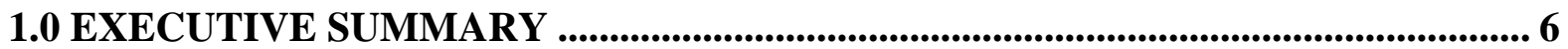

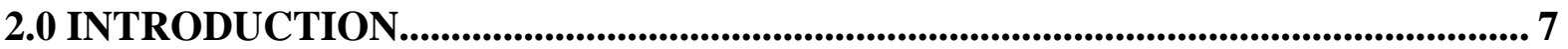

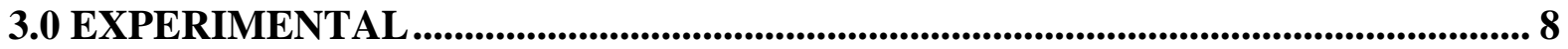

3.1 Scanning Electron Microscopic Characterization of Membrane Electrode

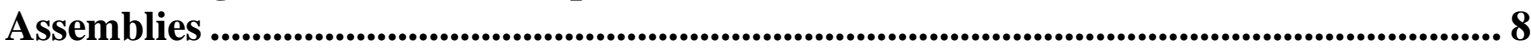

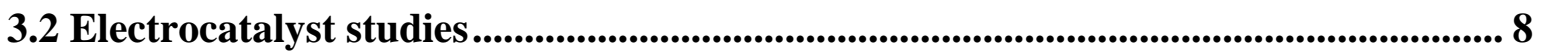

3.3 Small scale electrolyzer studies .......................................................................9

3.4 Empirical analysis of the Performance Curves ......................................................... 10

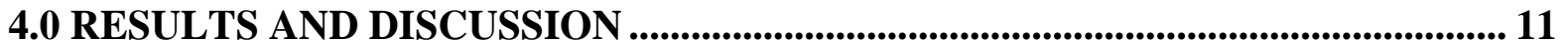

4.1 Post-mortem Scanning Electron Microscopic Characterization of Membrane

Electrode Assemblies............................................................................................................ 11

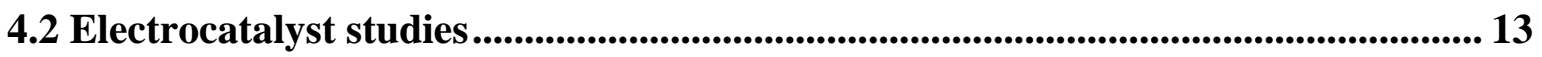

4.3 Small scale electrolyzer studies ....................................................................................... 14

4.4 Empirical analysis of the Performance Curves .................................................... 16

5.0 CONCLUSIONS AND RECOMMENDATIONS................................................. 21

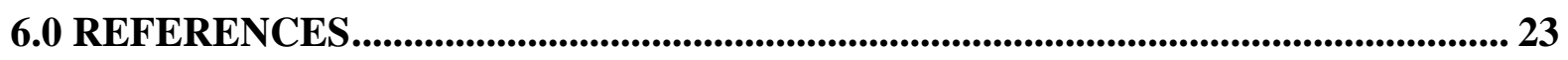




\section{LIST OF FIGURES}

Figure 1 Simplified schematic of the catalyst characterization cell .................................... 8

Figure 2 Simplified schematic of the small scale electrolyzer. ......................................... 9

Figure 3 Cross-section SEM micrograph of the MEAs after been tested for different times at $80{ }^{\circ} \mathrm{C}$ and 4 atmospheres: MEA-12- 105 hours (top) and MEA-13- 20 hours (bottom). Membrane for both MEAs is Nafion ${ }^{\circledR} 115$ and Pt/C catalyst for anode and cathode..... 12

Figure 4 Cross-section SEM micrograph of the MEAs after been tested at $80{ }^{\circ} \mathrm{C}$ and 4 atmospheres. MEA-9 (top) uses Nafion ${ }^{\circledR} 117$ and Pt black on both sides. MEA-20 (bottom) uses Nafion ${ }^{\circledR} 115$ and Pt black on the cathode and Pt/C catalyst for anode.... 13

Figure 5 Catalytic activity of Pt based catalysts for the oxidation of $\mathrm{SO}_{2}$ in $30 \mathrm{wt} \%$ acid and room temperature. ............................................................................................... 14

Figure 6 Effect of temperature and acid concentration on the current density of an MEA fabricated similar approach to MEA-8. Testing was performed under an applied potential of $1 \mathrm{~V}$ and $1 \mathrm{~atm}$.

Figure 7 Effect of temperature and acid concentration on the resistance of an MEA fabricated similar approach to MEA-8. Testing was performed under an applied potential of $1 \mathrm{~V}$ and $1 \mathrm{~atm}$.

Figure 8. Performance curve and model fit data for MEA-8, tested in the single cell SDE at $80{ }^{\circ} \mathrm{C}, 30 \mathrm{wt} \%$ acid and $2 \mathrm{~atm}$.

Figure 9. Ohmic overpotential for MEA-8 operated at $80{ }^{\circ} \mathrm{C}$ and $30 \mathrm{wt} \%$ acid at different pressures. The expected pure membrane resistance at the operating conditions is included as a reference.

Figure 10. Mass transport overpotential for MEA-8 operated at $80{ }^{\circ} \mathrm{C}$ and $30 \mathrm{wt} \%$ acid at different pressures.

Figure 11. Kinetic overpotential and equilibrium potential for MEA-8 operated at $80{ }^{\circ} \mathrm{C}$ and $30 \mathrm{wt} \%$ acid at different pressures. 
WSRC-STI-2008-00291, Rev. 0

\section{LIST OF TABLES}

Table 1 Contribution of overpotential terms for MEA \#8 at a current density.................... 20 


\subsection{EXECUTIVE SUMMARY}

Fiscal year 2008 studies in electrolyzer component development have focused on the characterization of membrane electrode assemblies (MEA) after performance tests in the single cell electrolyzer, evaluation of electrocatalysts and membranes using a small scale electrolyzer and evaluating the contribution of individual cell components to the overall electrochemical performance.

Scanning electron microscopic (SEM) studies of samples taken from MEAs testing in the SRNL single cell electrolyzer test station indicates a sulfur-rich layer forms between the cathode catalyst layer and the membrane. Based on a review of operating conditions for each of the MEAs evaluated, we conclude that the formation of the layer results from the reduction of sulfur dioxide as it passes through the MEA and reaches the catalyst layer at the cathode-membrane interface. Formation of the sulfur rich layer results in partial delamination of the cathode catalyst layer leading to diminished performance. Furthermore we believe that operating the electrolyzer at elevated pressure significantly increases the rate of formation due to increased adsorption of hydrogen on the internal catalyst surface. Thus, identification of a membrane that exhibits much lower transport of sulfur dioxide is needed to reduce the quantity of sulfur dioxide that reaches the cathode catalyst and is reduced to produce the sulfur-rich layer. Three candidate membranes are currently being evaluated that have shown promise from preliminary studies, (1) modified Nafion ${ }^{\circledR}$, (2) polybenzimidazole (PBI), and (3) sulfonated Diels Alder polyphenylene (SDAPP).

Testing examined the activity for the sulfur dioxide oxidation of platinum (Pt) and platinumalloy catalysts in $30 \mathrm{wt} \%$ sulfuric acid solution. Linear sweep voltammetry showed an increase in activity when catalysts in which Pt is alloyed with non-noble transition metals such as cobalt and chromium. However when Pt is alloyed with noble metals, such as iridium or ruthenium, the kinetic activity decreases. We recommend further testing to determine if these binary alloys will provide the increased reaction kinetic needed to meet the targets. We also plan to test the performance of these catalyst materials for both proton and sulfur dioxide reduction. The latter may provide another parameter by which we can control the reduction of sulfur dioxide upon transport to the cathode catalyst surface.

A small scale electrolyzer $\left(2 \mathrm{~cm}^{2}\right)$ has been fabricated and successfully installed as an additional tool to evaluate the effect of different operating conditions on electrolyzer and MEA performance. Currently this electrolyzer is limited to testing at temperatures up to 80 ${ }^{\circ} \mathrm{C}$ and at atmospheric pressure.

Selected electrochemical performance data from the single cell sulfur dioxide depolarized electrolyzer were analyzed with the aid of an empirical equation which takes into account the overpotential of each of the components. By using the empirical equation, the performance data was broken down into its components and a comparison of the potential losses was made. The results indicated that for the testing conditions of $80{ }^{\circ} \mathrm{C}$ and $30 \mathrm{wt} \%$ sulfuric acid, the major overpotential contribution ( $70 \%$ of all losses) arise from the slow reaction rate of oxidation of sulfur dioxide. The results indicate that in order to meet the target of hydrogen production at $0.5 \mathrm{~A} / \mathrm{cm}^{2}$ at $0.6 \mathrm{~V}$ and $50 \mathrm{wt} \%$ sulfuric acid, identification of a better catalyst for sulfur dioxide oxidation will provide the largest gain in electrolyzer performance. 


\subsection{INTRODUCTION}

Concerns about the dependence on petroleum imports, poor air quality, and greenhouse emissions have accelerated the development of energy systems using hydrogen as an energy carrier. Hydrogen can be extracted using a variety of technologies, which can be divided in three main categories: thermal, electrochemical, and biological. Among the production methods water electrolysis is a well established technology, which is capable of producing emission free hydrogen if used in conjunction with renewable or nuclear energy [1]. However, the technology and energy inputs for the electrolysis process can make the production of hydrogen by this method expensive. In order to produce global scale quantities of hydrogen in a more energy efficient process, thermochemical water splitting cycles using heat from a nuclear reactor have been proposed and developed since the late 1960s [2]. Among the many possible thermochemical cycles for the production of hydrogen, the sulfurbased cycles lead the competition in overall energy efficiency.

A variant on sulfur-based thermochemical cycles is the Hybrid Sulfur (HyS) Process. The HyS cycle uses a sulfur dioxide-depolarized electrolyzer (SDE) to produce hydrogen. The electrolyzer oxidizes sulfur dioxide to form sulfuric acid at the anode [r1] and reduces protons to form hydrogen at the cathode [r2]. The overall electrochemical cell reaction consists of the production of $\mathrm{H}_{2} \mathrm{SO}_{4}$ and $\mathrm{H}_{2}$ [r3]. The key attribute of the reactions occurring in the SDE is the anodic reaction [r1], which occurs at a standard half cell potential of -0.158 $\mathrm{V}$ vs. standard hydrogen electrode (SHE) [3]. Compared with low temperature pure water electrolysis, which occurs at $-1.23 \mathrm{~V}$ vs. SHE, the SDE could potentially produce the same amount of hydrogen with almost one eighth of the power used in conventional electrolysis.

$$
\begin{gathered}
\mathrm{SO}_{2}(a q)+2 \mathrm{H}_{2} \mathrm{O}(l) \rightarrow \mathrm{H}_{2} \mathrm{SO}_{4}(a q)+2 \mathrm{H}^{+}(a q)+2 e^{-} \\
2 \mathrm{H}^{+}+2 e^{-} \rightarrow \mathrm{H}_{2} \\
\mathrm{SO}_{2}+2 \mathrm{H}_{2} \mathrm{O} \rightarrow \mathrm{H}_{2} \mathrm{SO}_{4}+\mathrm{H}_{2}
\end{gathered}
$$

Original work on the development of a SDE featured a parallel-plate electrolyzer with a separator or membrane to keep the anolyte and catholyte compartments separate. Precious metal blacks were used as electrocatalysts [4]. Since this work was completed in the early 1980s, significant advances have occurred in electrolyzer technology principally in the area of hydrogen fuel cells. The use of state of the art polymer electrolyte membrane (PEM) electrolyzer technology was incorporated in the SDE design by Steimke et al. [5,6]. In the redesigned electrolyzer, $\mathrm{SO}_{2}$ dissolved in sulfuric acid is flowed to the anode while hydrogen is produced at the dry cathode. The incorporation of the PEM technology in the SDE design provides a considerable improvement in performance mainly due to a decrease in IR losses across the cell and better utilization of the catalyst layer.

Sivasubramanian et al. have studied a different operating strategy for the PEM-based SDE [7]. In this operational mode dry $\mathrm{SO}_{2}$ is flowed into the anode side and water is pumped through the cathode side. While this system shows improved mass transfer characteristics for $\mathrm{SO}_{2}$, the system is limited by the amount of water that diffuses from the cathode side to the anode for reaction with $\mathrm{SO}_{2}$.

While both of these approaches solve many of the engineering problems associated with the original SDE design, further development of the PEM concept is required for commercial 
deployment of the SDE. In this report the performance curves obtained in our single cell SDE are analyzed and the energy losses from the individual components identified. With the voltage losses identified, the optimization of the membrane-electrode structure and materials can be optimized. We also report results of catalysts studies that indicate improved performance using binary and ternary alloy catalysts containing platinum and other transition metals.

\subsection{EXPERIMENTAL}

\subsection{SCANNING ELECTRON MICROSCOPIC CHARACTERIZATION OF MEMBRANE ELECTRODE ASSEMBLIES}

MEAs were removed from the single cell electrolyzer and rinsed with distilled water to remove any traces of sulfuric acid. Approximately 1-inch squares of the MEA were cut from the center of the MEA, briefly air-dried and imbedded into an epoxy resin. After the epoxy cures, the embedded sample is exposed by polishing to a mirror finish. After polishing sample is coated with a thin layer of gold to make the surface conductive and prevent surface charging. The polished and coated sample is then placed into the scanning electron microscope (SEM). Energy dispersive X-ray spectroscopy (EDX) is used to provide semiquantitative data as to the elemental composition of each of the layers of the MEA.

\subsection{ELECTROCATALYST STUDIES}

The catalyst activity and stability was evaluated using the three electrode cells shown in Figure 1. The cell consists of a glass vial with a Teflon cap and a water jacket. The three electrodes, which included a silver-silver chloride reference electrode, a platinum wire as the auxiliary electrode, and a glassy carbon disk electrode coated with the test catalyst, were inserted through the Teflon cap.

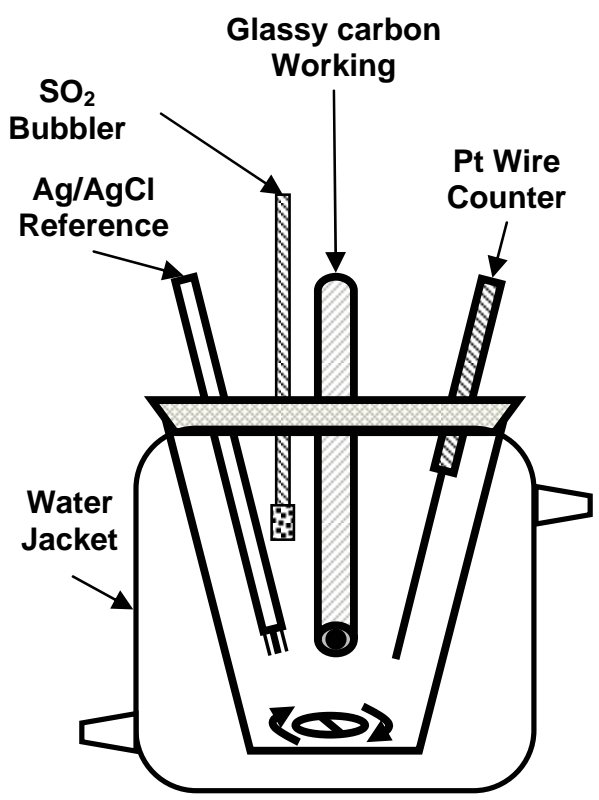

Figure 1 Simplified schematic of the catalyst characterization cell 
During measurements the cell was filled with concentrated sulfuric acid and purged of oxygen by flowing nitrogen. Electrochemical characterization of catalysts consisted of cyclic voltammograms (CVs) in the solution purged with nitrogen and linear sweep voltammograms (LSVs) in $\mathrm{SO}_{2}$ saturated sulfuric acid solutions. The CVs were performed at a scan rate of $50 \mathrm{mV} / \mathrm{sec}$ and in a potential window between $1004 \mathrm{mV}$ and $-100 \mathrm{mV}$ vs. $\mathrm{Ag} / \mathrm{AgCl}$. The LSVs were performed in the potential window between $804 \mathrm{mV}$ and $104 \mathrm{mV}$ vs. Ag/AgCl at a scan rate of $5 \mathrm{mV} / \mathrm{sec}$. The experiments were carried out at room temperature and at $30 \mathrm{wt} \%$ sulfuric acid concentration. The curves were repeated until a stable performance was obtained. Both measurements were performed starting from the anodic potential and going in the cathodic direction.

\subsection{SMALL SCALE ELECTROLYZER STUDIES}

The membrane electrode assemblies (MEAs) were evaluated using a custom made glass electrolyzer cell; a schematic of the cell is shown in Figure 2. The cell consists of two glass chambers joined by a Teflon ${ }^{\mathrm{TM}} /$ graphite bridge where the MEA is secured. On both sides of the MEA carbon paper and carbon cloth are used as flow distributors for the anode (left) and cathode (right), respectively. A peristaltic pump was used to drive the $\mathrm{SO}_{2}$ saturated acid through the graphite flow field and subsequently the anode diffusion media, while $\mathrm{H}_{2}$ gas produced at the cathode was allowed to escape through the diffusion media. During a typical experiment the left chamber is filled with the concentrated acid of interest and the right chamber is filled with deionized water. Then the cell temperature is adjusted and allowed to stabilize. Once the system temperature is stable, oxygen is purged by flowing nitrogen into both chambers. The flow rate of the sulfuric acid solution is set and a constant voltage is applied across the cell. After a minute, $\mathrm{SO}_{2}$ is bubbled into the acid chamber resulting in the electrochemical production of hydrogen and sulfuric acid.

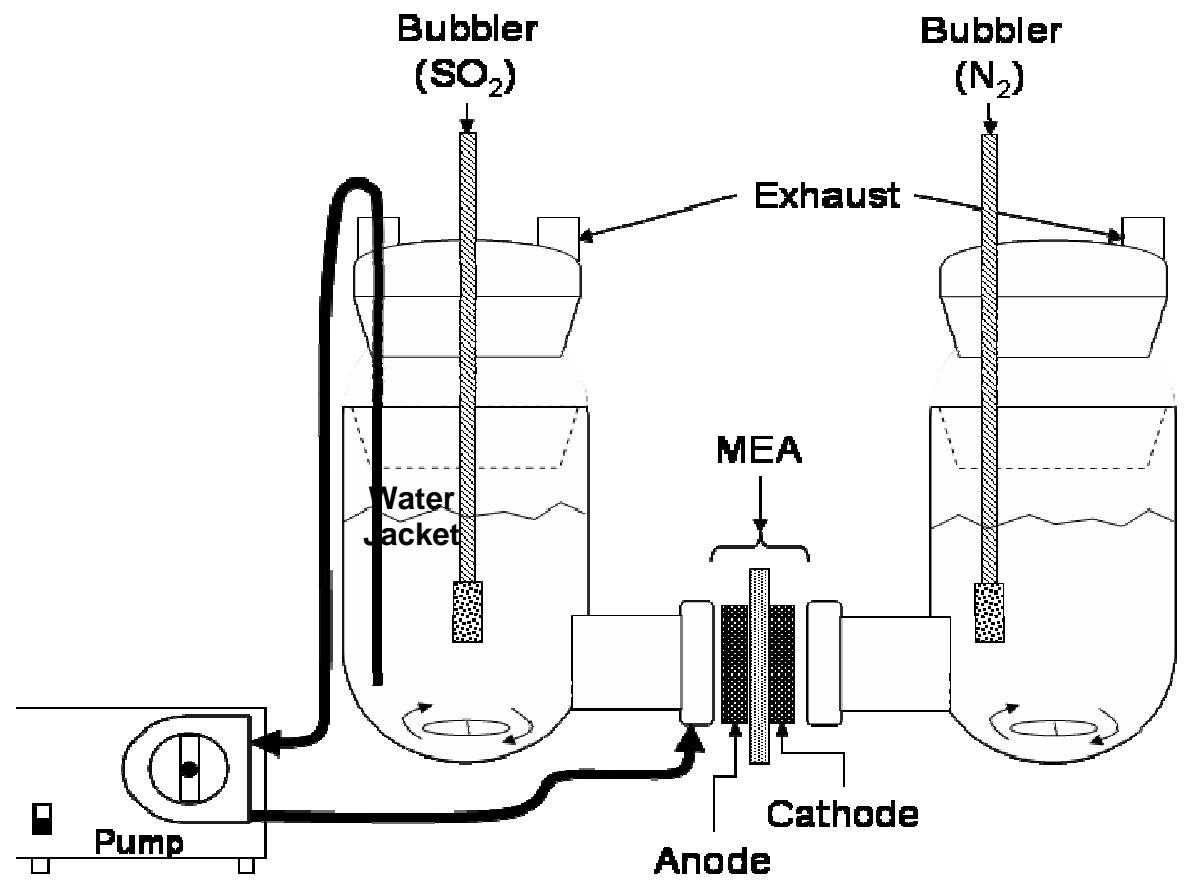

Figure 2 Simplified schematic of the small scale electrolyzer. 
The voltage is controlled using a programmable PARSTAT 2273 potentiostat/frequency analyzer from Princeton Applied Research, capable of operating the cell at current densities up to $1 \mathrm{~A} / \mathrm{cm}^{2}$. During the experiments the cell resistance was measured as a function of time at the voltage of interest. The resistance was measured using electrochemical impedance spectroscopy (EIS) technique. During EIS measurements, a $10 \mathrm{mV}$ vs. $1 \mathrm{~V}$ sinusoidal voltage was imposed across the membrane at frequencies between $500 \mathrm{kHz}$ and $200 \mathrm{~Hz}$. The resulting response was plotted in the form of Nyquist plots. The resistance was calculated from the value of the real impedance when the imaginary response is zero.

\subsection{EMPIRICAL ANALYSIS OF THE PERFORMANCE CURVES}

Generally, the potential losses inside the SDE can be identified as the reversible cell voltage, at the interfaces between solid/fluid phases and internally to each of the single phases (e.g., sulfuric acid solution). The reversible cell voltage, $E^{o}$, provides the thermodynamic cell potentials at near equilibrium and can be calculated from the Nernst's equation. The internal single phase losses are essentially Ohmic losses which vary linearly with the cell current density. These losses can be summarized inside the $i R A$ term in which $R$ denotes the cell resistance, $A$ the cell area and $i$ the current density.

The more complex behavior originates in the small electrode reactive regions where the liquid phase and the solid phases coexist. In these regions two main factors govern the magnitude of the interface overpotentials: the reaction kinetics and the local availability of reactants. The typical assumption in the reaction kinetic overpotential is that the cathodic contribution, [r2], is small compared to the anodic contribution, [r3], which is generally justified by pure $\mathrm{H}_{2}$ operation, therefore kinetic overpotential can be simplified to the anode electrode Tafel equation, $b \log \left(i / i_{o}\right)$, in which $b$ denotes the Tafel slope and $i_{o}$ the exchange current density.

The availability of reactants or mass transport overpotential can be based on Fick's law of diffusion, $R T / n F \ln \left(i_{\max } /\left(i_{\max }-i\right)\right)$, multiplied with an amplification term, $\alpha\left(i / i_{0}\right)^{k}$, in which $R$ is the ideal gas constant, $T$ is the temperature, $n$ is the number of electrons transferred, $F$ is Faradays constant and $i_{\max }$ is the mass transport limited current density. The amplification term takes into account nonlinear effects arising from mutual contributions of different membrane electrode assembly, MEA, components such as catalyst layer.

In this work, the individual losses of the cell performance will be analyzed by fitting the experimental data to the empirical equation consisting on the addition of the overpotential terms described above [8]. The empirical equation used is as follows:

$$
\begin{aligned}
& E=\stackrel{\substack{\text { Kinetic } \\
\text { Equilibrium } \\
\text { Potential }}}{E_{\text {Cell }}^{o}}+b \log \left(\frac{i}{i_{o}}\right)+\stackrel{\substack{\text { Ohmic } \\
\text { Overpotential }}}{i R A+}+\begin{array}{c}
\begin{array}{c}
\text { Mass Transport } \\
\text { Overpotential }
\end{array} \\
\eta_{c}
\end{array} \\
& \eta_{c}=\alpha\left(\frac{i}{i_{o}}\right)^{k} \frac{R T}{z F} \ln \left(\frac{i_{\max }}{i_{\max }-i}\right)
\end{aligned}
$$




\subsection{RESULTS AND DISCUSSION}

\subsection{POST-MORTEM SCANNING ELECTRON MICROSCOPIC CHARACTERIZATION OF MEMBRANE ELECTRODE ASSEMBLIES}

Four MEAs were analyzed after $\mathrm{SO}_{2}$ electrolysis testing in order to study the sulfur layer growth after several hours of operation. The first two MEAs were prepared almost identical by depositing the catalyst layer directly on Nafion ${ }^{\circledR} 115$. Figure 3 shows the cross-section SEM micrograph of the MEAs after being tested at $80{ }^{\circ} \mathrm{C}$ and 4 atmospheres. From the posttest images of the MEAs, a sulfur-rich layer forms between the membrane and cathode catalyst layer. This finding indicates that unreacted sulfur dioxide crosses from the anode through the membrane and is reduced to sulfur as soon as it encounters the cathode catalyst layer. The sulfur-rich layer continues to grow with increased operating time of the electrolyzer.

Analysis of MEA-9 (see Figure 4) revealed no evidence of a sulfur-rich layer. Since this MEA, prepared by Giner Electrochemical Systems, uses Pt black catalyst layers for the anode and cathode and contains a low carbon content, we postulated that formation of the sulfur layer may be enhanced by the presence of the carbon support onto which the Pt catalyst was formed in the MEAs (see Figure 3 with MEA-12 and MEA-13). The sulfur may be reduced electrochemically at the carbon surface or undergo a chemical reduction reaction with adsorbed hydrogen.

To test this hypothesis we prepared and tested MEA-20, which contains a cathode catalyst layer of Pt black and anode catalyst layer of Pt/C. The bottom image of Figure 4 shows a sulfur rich layer in MEA-20. From the elemental analysis one can observe that the carbon content is high compared to MEA 9. Because of the high carbon content, we cannot rule out that low carbon content will reduce the formation of the sulfur-rich layer from this experiment.

Subsequently, we tested MEAs with Pt black and Pt/C catalyst layers in the small scale electrolyzer (see Section 4.3). To date, a sulfur-rich layer has not been observed in any of the MEAs tested in the small scale electrolyzer. A sulfur-rich layer has not been observed in the MEA obtained from the gas-fed electrolyzer operated at the University of South Carolina (USC). The single cell electrolyzer using MEA-9 (Pt black cathode catalyst) also was only operated at atmospheric pressure. Since both the small-scale and the USC electrolyzers were also operated at atmospheric pressure, we believe that pressure is a key parameter in the formation of the sulfur-rich region. At higher operating pressure, adsorbed hydrogen is likely present in the cathode catalyst region that can react with sulfur dioxide to produce the sulfur-rich phase. Tests are underway to confirm this hypothesis. 
WSRC-STI-2008-00291, Rev. 0
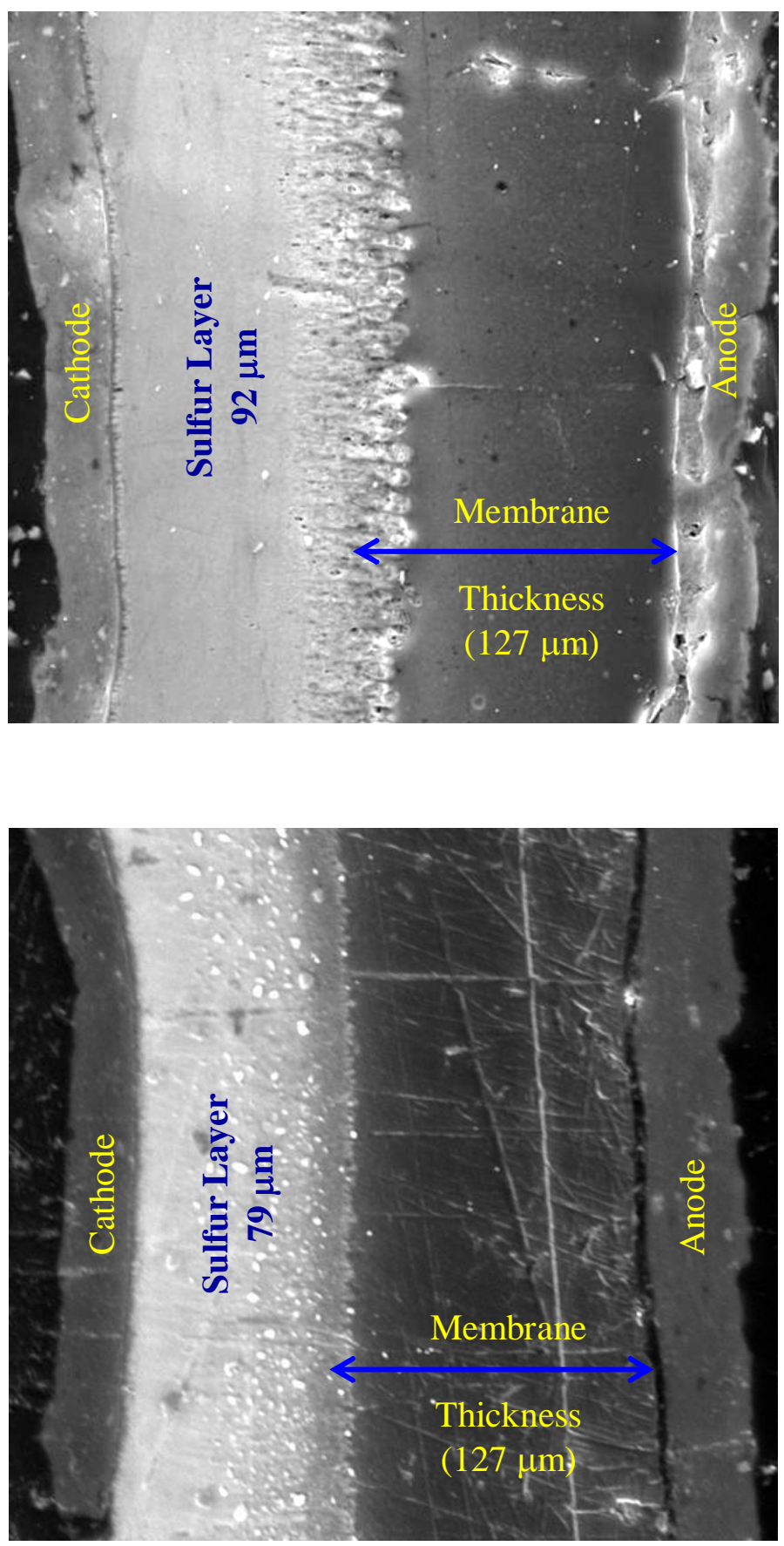

Figure 3 Cross-section SEM micrograph of the MEAs after been tested for different times at $80{ }^{\circ} \mathrm{C}$ and 4 atmospheres: MEA-12- 105 hours (top) and MEA-13- 20 hours (bottom). Membrane for both MEAs is Nafion ${ }^{\circledR} 115$ and $\mathrm{Pt} / \mathrm{C}$ catalyst for anode and cathode. 
WSRC-STI-2008-00291, Rev. 0
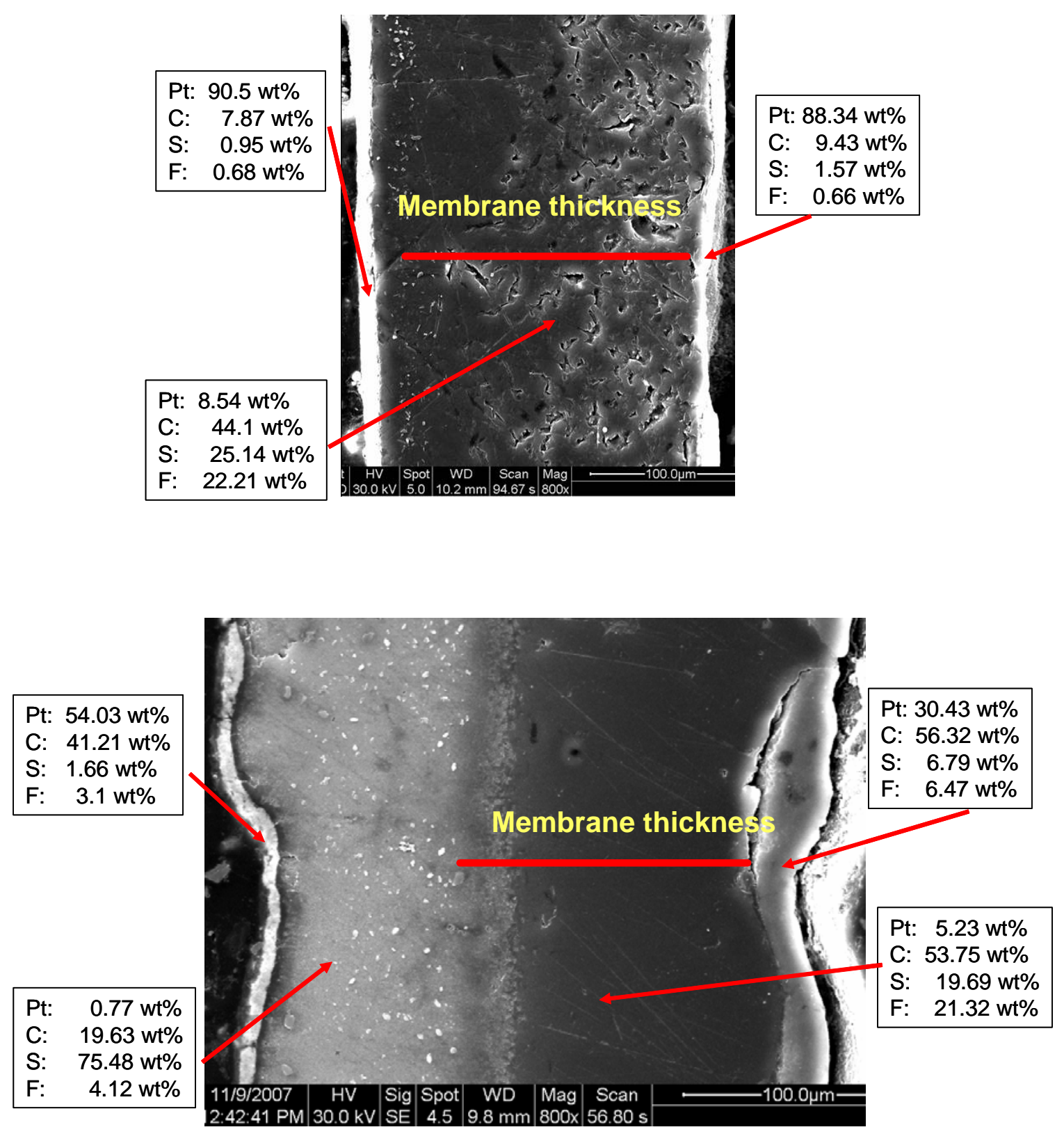

Figure 4 Cross-section SEM micrograph of the MEAs after been tested at $80{ }^{\circ} \mathrm{C}$ and 4 atmospheres. MEA-9 (top) uses Nafion ${ }^{\circledR} 117$ and Pt black on both sides. MEA-20 (bottom) uses Nafion ${ }^{\circledR} 115$ and Pt black on the cathode and Pt/C catalyst for anode.

\subsection{ELECTROCATALYST STUDIES}

Selecting the right catalyst will have an impact on the electrical efficiency by allowing the SDE to operate at conditions closer to the reversible potential (0.17 V vs. SHE). The electrocatalytic activity of the Pt base catalysts was investigated for the oxidation of $\mathrm{SO}_{2}$ in $30 \mathrm{wt} \%$ sulfuric acid solutions at room temperature. The potential current relationship is shown in Figure 5 in the form of Tafel plots. It can be seen from the plots how the voltage close to open circuit potential and the exchange current density varies depending on the 
transition metal Pt is being alloyed. It is interesting to note that the best performance is observed when Pt is alloyed with non-noble metals such as cobalt and chromium. Note, however, when Pt is alloyed with noble metals such as iridium or ruthenium the performance is decreased.

From Figure 5, the best performance was measured with a catalyst featuring Pt alloyed with $\mathrm{Co}$ and Cr. This catalyst produced a $20 \mathrm{mV}$ decrease in the potential compared to the baseline Pt/C catalyst. Note, however, that a decrease in the potential of about $150 \mathrm{mV}$ is needed to achieve the performance target. Thus, there is a need to further increase the anode catalyst performance for the oxidation of sulfur dioxide.

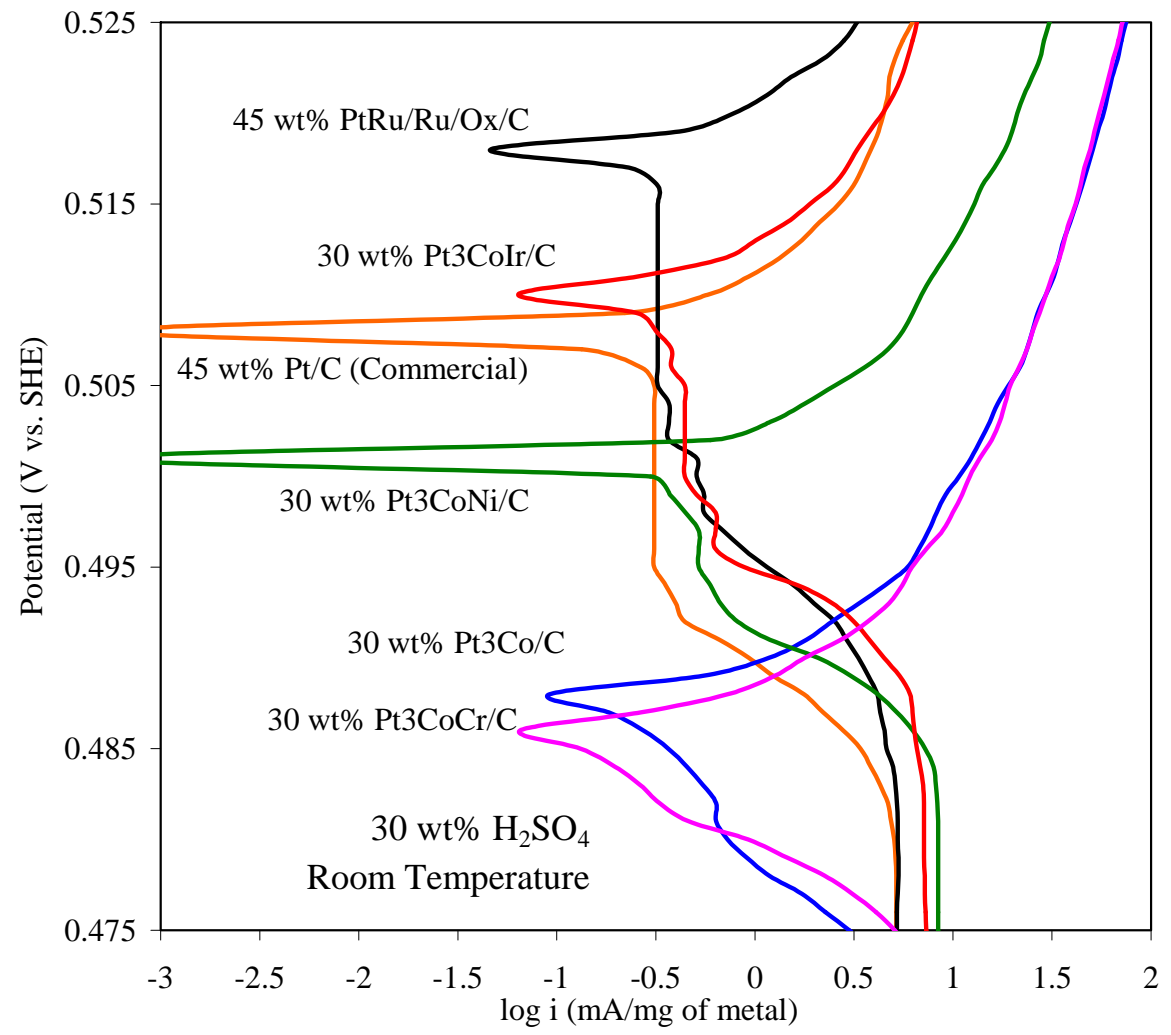

Figure 5 Catalytic activity of Pt based catalysts for the oxidation of $\mathrm{SO}_{2}$ in $30 \mathrm{wt} \%$ acid and room temperature.

\subsection{SMALL SCALE ELECTROLYZER STUDIES}

As part of the component development activity, a small scale electrolyzer $\left(2 \mathrm{~cm}^{2}\right.$ working area) was fabricated and installed in FY08 to augment MEA performance testing in the larger $\left(60 \mathrm{~cm}^{2}\right)$ single cell electrolyzer. As part of the baseline study, the performance of an MEA similar to MEA-8 (previously tested in the single cell electrolyzer) was tested to study the effect of different acid concentrations and temperatures at atmospheric pressures and an applied voltage of $1 \mathrm{~V}$. 
Figure 6 and Figure 7 show the effects of temperature and acid concentration on the current density and MEA resistance, respectively. As can be observed in Figure 6, the current density increases as the temperature increases until it reaches a maximum at around $70{ }^{\circ} \mathrm{C}$. Above $70{ }^{\circ} \mathrm{C}$, the current density declines rapidly. Since the flowrate is being kept constant, the increase in current is an indication of improved kinetics and conductivity. However, as the temperature increases the concentration of $\mathrm{SO}_{2}$ decreases due to the lower solubility of $\mathrm{SO}_{2}$ and the system becomes mass transport limited resulting in the decrease in the current density.

The MEA resistance decreases with increasing temperature over all temperatures in $30 \mathrm{wt} \%$ sulfuric acid and up to about $70{ }^{\circ} \mathrm{C}$ in 46 and $64 \mathrm{wt} \%$ sulfuric acid (see Figure 7). The decrease in resistance reflects an enhancement in ionic conductivity with increasing temperature.

The effect on the acid concentration can also be observed in the figures. As the acid wt\% is increased the current response decreases and the resistance increases. This decrease in performance can be attributed to combination of the following, (1) a decrease in the $\mathrm{SO}_{2}$ concentration, (2) a decrease in the $\mathrm{SO}_{2}$ oxidation kinetics and (3) a decrease in the conductivity due to the dehydration of the membrane.

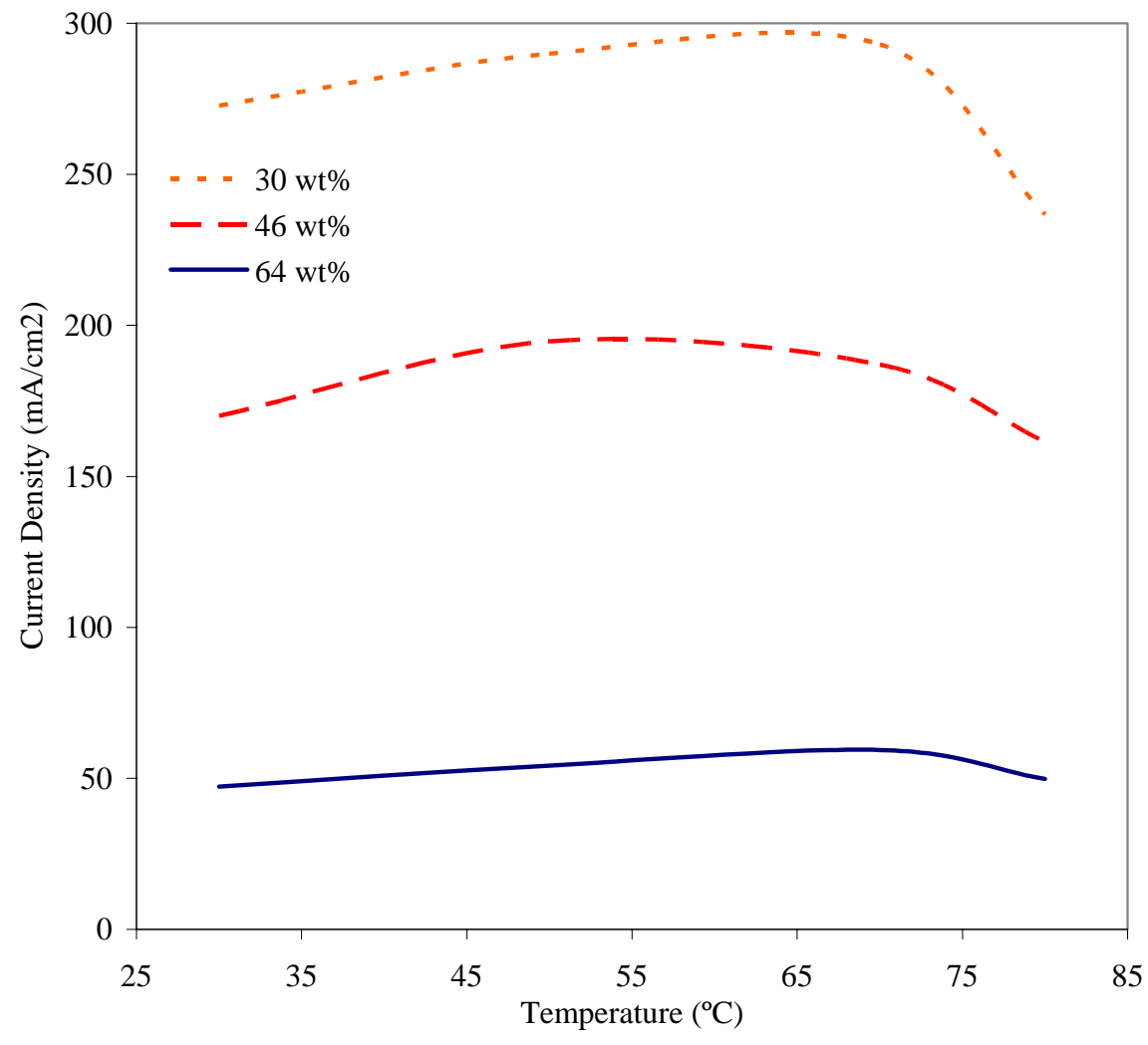

Figure 6 Effect of temperature and acid concentration on the current density of an MEA fabricated similar approach to MEA-8. Testing was performed under an applied potential of $1 \mathrm{~V}$ and $1 \mathrm{~atm}$. 
WSRC-STI-2008-00291, Rev. 0

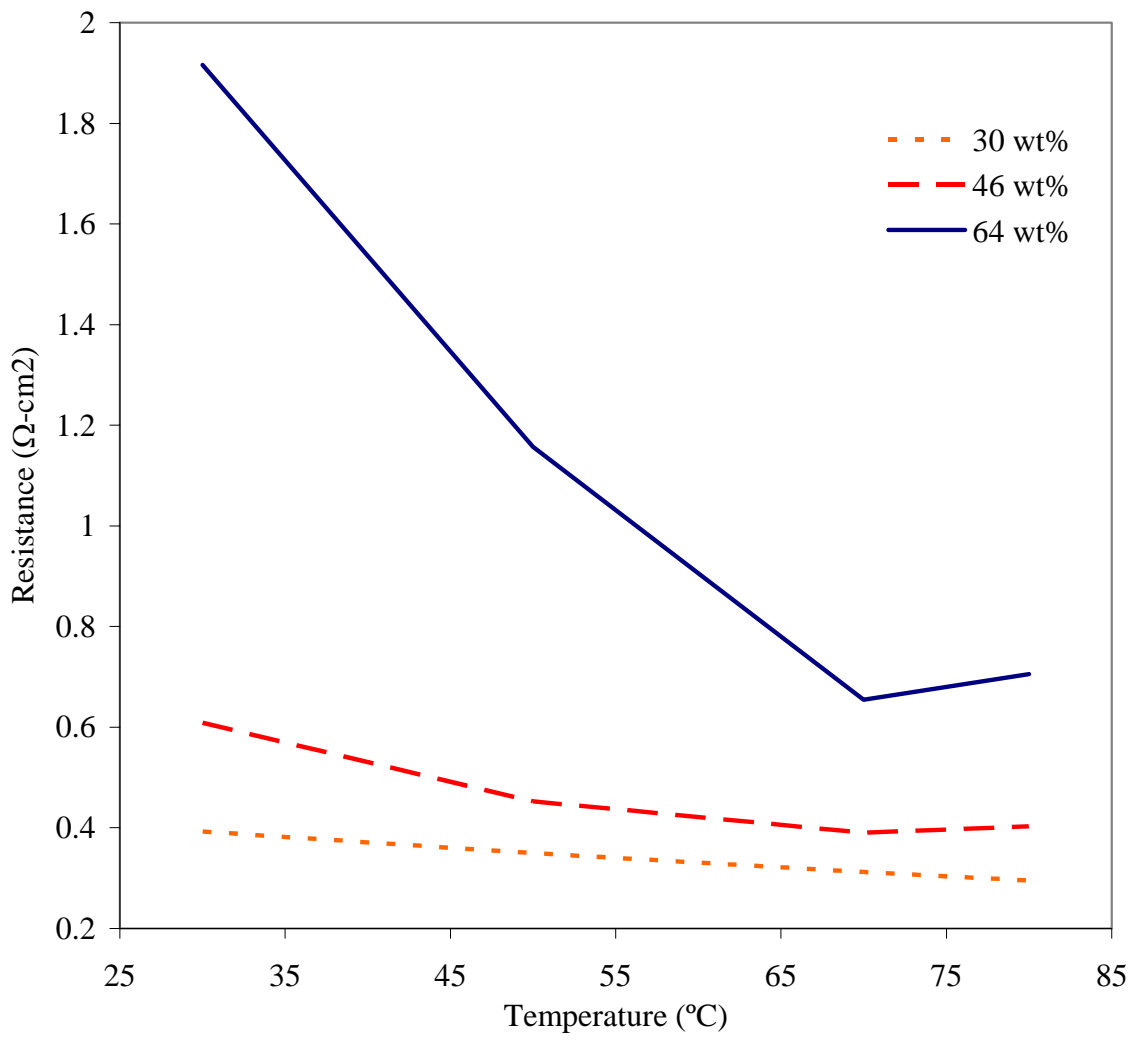

Figure 7 Effect of temperature and acid concentration on the resistance of an MEA fabricated similar approach to MEA-8. Testing was performed under an applied potential of $1 \mathrm{~V}$ and $1 \mathrm{~atm}$.

\subsection{EMPIRICAL ANALYSIS OF THE PERFORMANCE CURVES}

The performance data obtained for MEA-8 in the single cell SDE was analyzed to obtain a better understanding of the potential loss magnitude due to the effect of operating conditions and different components used in the MEA. MEA-8 is comprised of an anode catalyst layer with $0.8 \mathrm{mg} \mathrm{cm}^{-2}$ of platinum and a cathode catalyst layer with $0.6 \mathrm{mg} \mathrm{cm}^{-2}$ of platinum heat pressed on to a Nafion ${ }^{\circledR}$ membrane $127 \mu \mathrm{m}$ thick. The MEA was tested at $80{ }^{\circ} \mathrm{C}, 30 \mathrm{wt} \%$ acid and operating pressures ranging from $1 \mathrm{~atm}$ up to $4 \mathrm{~atm}$. The typical performance of this MEA is shown in Figure 8, where the symbols correspond to the experimental data obtained at 2 atm and the solid line corresponds to the model fit using [eq1]. 


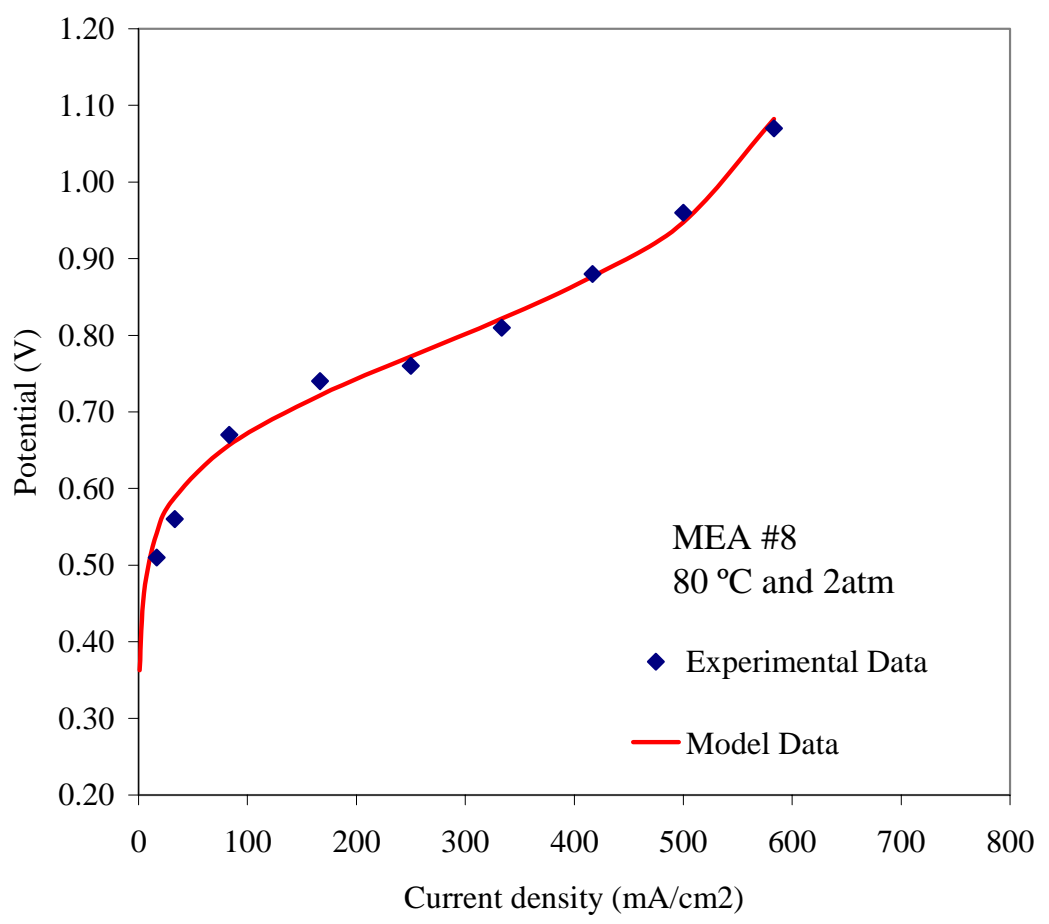

Figure 8. Performance curve and model fit data for MEA-8, tested in the single cell $\mathrm{SDE}$ at $80{ }^{\circ} \mathrm{C}, 30 \mathrm{wt} \%$ acid and $2 \mathrm{~atm}$.

As can be observed from Figure 8, equation 1 is able to fit all the different regions of the performance curve. Similar fits were obtained at the different pressures ranging from 1 to 4 atmospheres. In the next figures, the breakdown of the different overpotential terms that make up [eq1] are shown. These terms include ohmic overpotential, kinetic overpotential, and mass transport overpotential.

Ohmic overpotential incorporates the voltage losses in the system that follows a linear behavior. This term incorporates losses in the form of resistances coming from the cell fixture, flow field, current collector, diffusion layer and the MEA. In a well design system, most of the resistance derives from the MEA, the diffusion layers and the contact resistance between the two layers. This region corresponds to the linear portion of the performance curve.

Figure 9 shows the ohmic term fitted at different operating pressures. To serve as a reference point, the pure membrane resistance expected at the operating conditions is included. Notice that the resistance at the different pressures is slightly larger than that of the pure membrane. This result is expected since the fitted measured resistance incorporates the contribution of the different layers. 


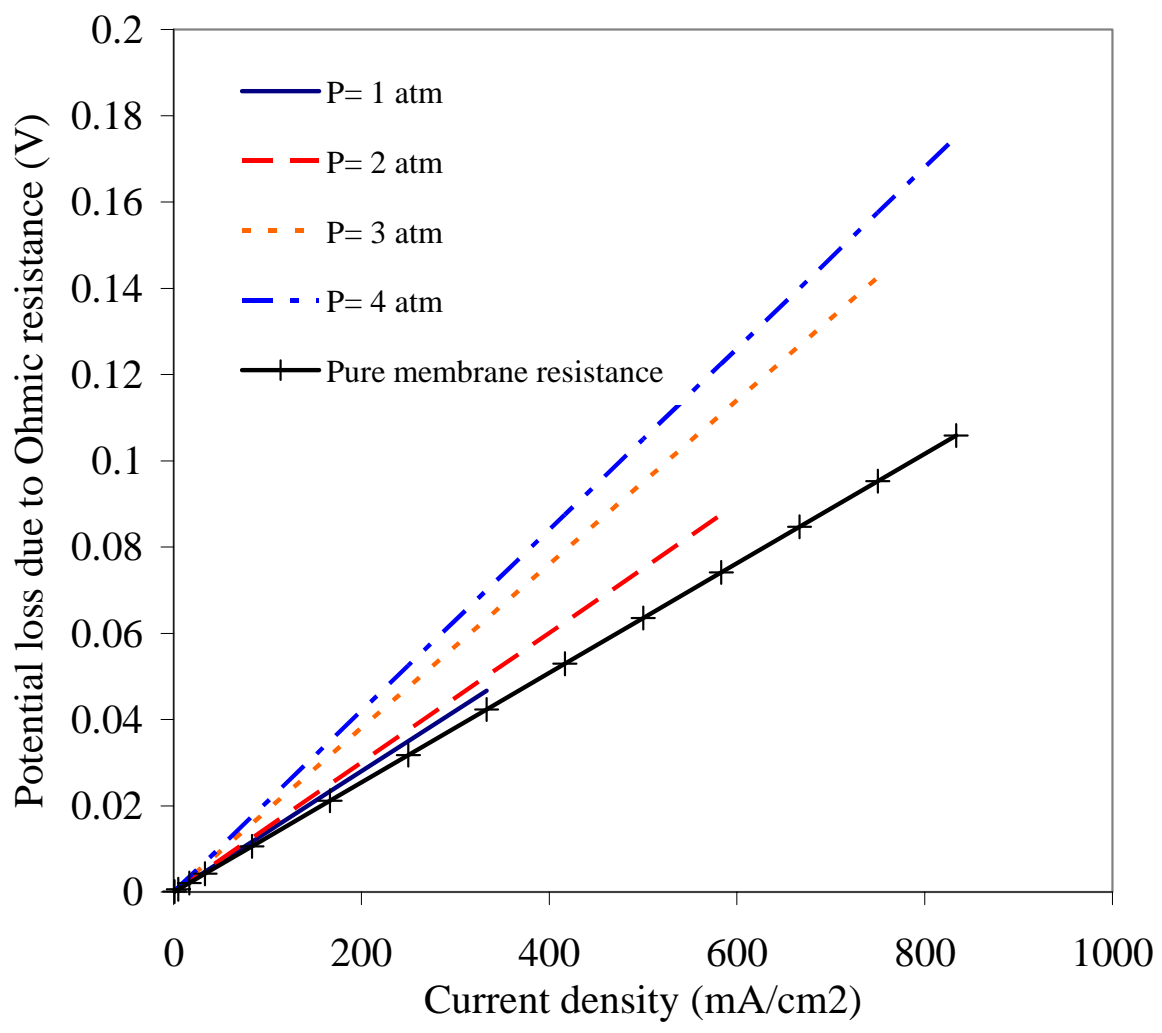

Figure 9. Ohmic overpotential for MEA-8 operated at $80^{\circ} \mathrm{C}$ and $30 \mathrm{wt} \%$ acid at different pressures. The expected pure membrane resistance at the operating conditions is included as a reference.

The mass transport overpotential term incorporates the voltage losses in the system that arises from the lack of reactants. This term is mostly influenced by concentration of reactants, flow distribution media, flow rate, and catalyst layer thickness. During the test of MEA-8, the pressure of the system was increased, which changes the concentration of sulfur dioxide in the anolyte. Calculations indicate that the concentration of sulfur dioxide varies from approximately $1 \mathrm{~g}$ of $\mathrm{SO}_{2} / 100 \mathrm{~g} \mathrm{H}_{2} \mathrm{SO}_{4}$ to $2.8 \mathrm{~g}$ of $\mathrm{SO}_{2} / 100 \mathrm{~g}$ of $\mathrm{H}_{2} \mathrm{SO}_{4}$, when operating the cell at pressures varying from 1 atm to $4 \mathrm{~atm}$ [9]. The mass transport overpotential affects the region corresponding to the high current densities where the rate of $\mathrm{SO}_{2}$ consumption is the highest. Figure 10 shows the mass transport term fitted at different operating pressures. 
WSRC-STI-2008-00291, Rev. 0

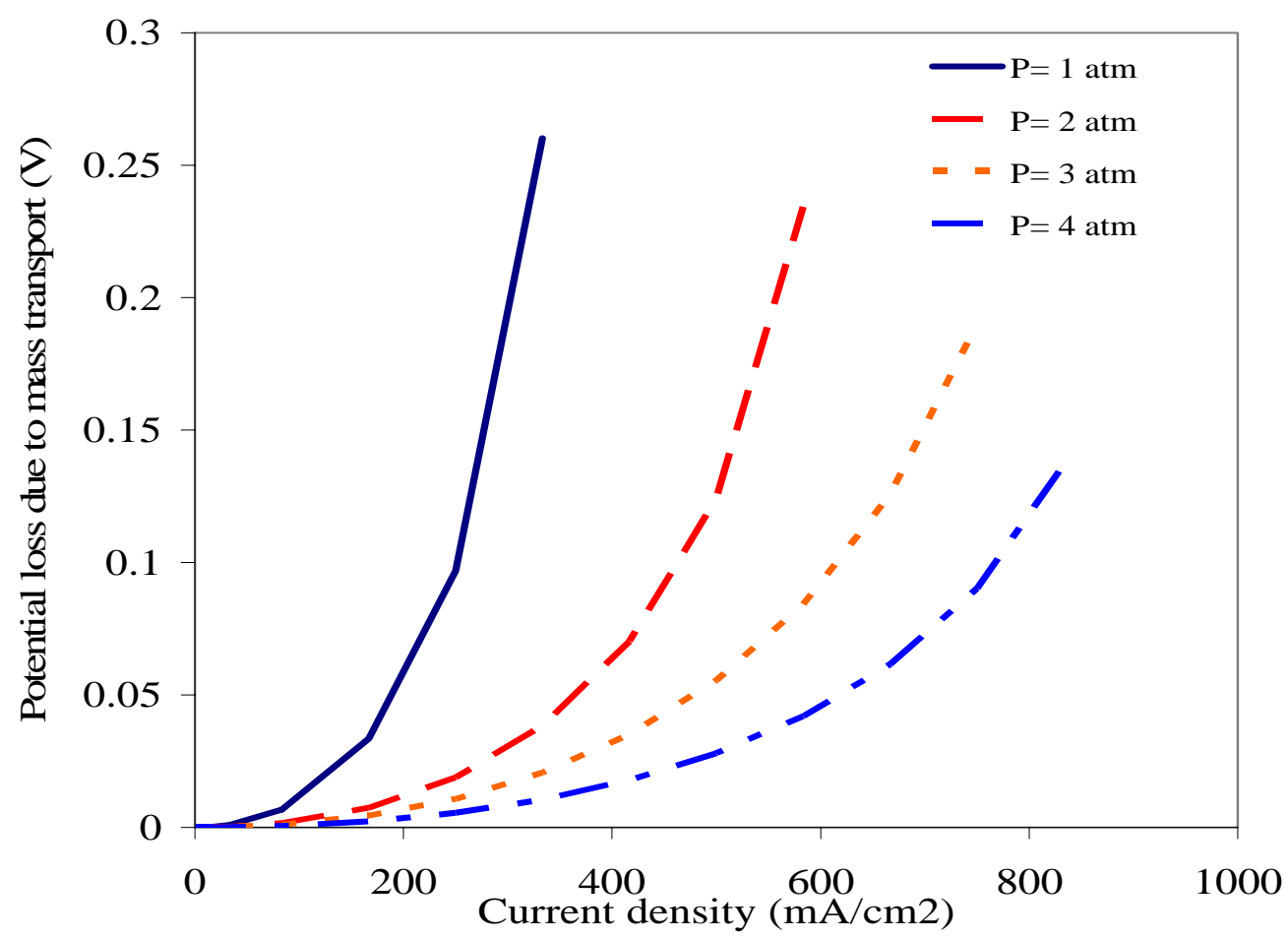

Figure 10. Mass transport overpotential for MEA-8 operated at $80{ }^{\circ} \mathrm{C}$ and $30 \mathrm{wt} \%$ acid at different pressures.

The kinetic overpotential term incorporates the voltage losses in the system that arises from rate of reaction. As discussed in the experimental section, for the present calculation the cathode reaction rate is assumed to be several orders faster than the anode reaction rate and, therefore, making the anode the major contributor (i.e., rate limiting term). The kinetic overpotential term affects the region corresponding to the low current densities where the rate of $\mathrm{SO}_{2}$ consumption is the lowest. Figure 11 shows the kinetic term fitted at different operating pressures. Included in Figure 6 is the equilibrium potential, which serves as the starting point for the overpotentials. 


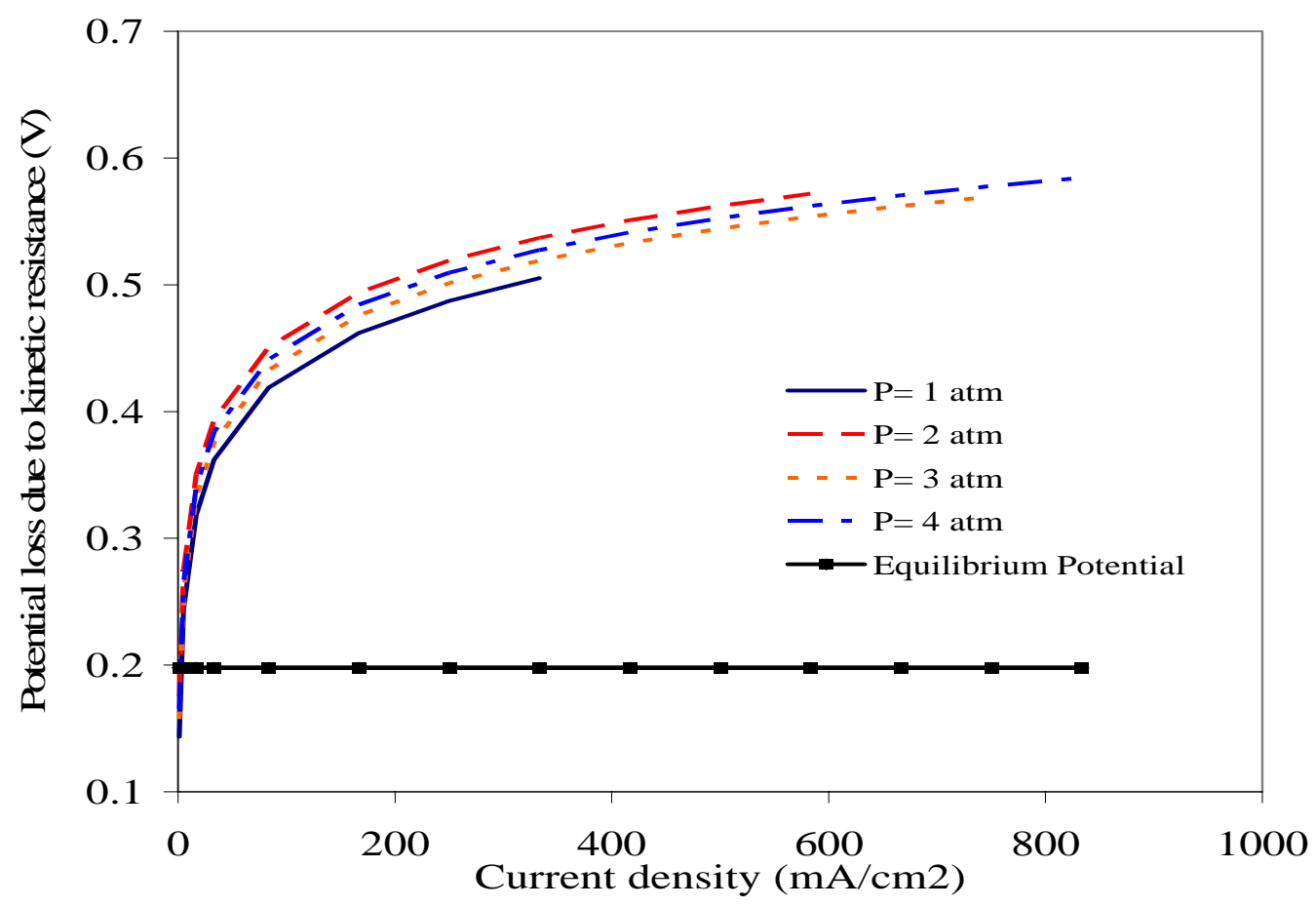

Figure 11. Kinetic overpotential and equilibrium potential for MEA-8 operated at 80 ${ }^{\circ} \mathrm{C}$ and $30 \mathrm{wt} \%$ acid at different pressures.

From the above results, the percentage overpotential contribution of each of the terms can be calculated at the performance target of $500 \mathrm{~mA} / \mathrm{cm}^{2}$ for the SDE. Table 1 shows the different contributions at a current density of $500 \mathrm{~mA} / \mathrm{cm}^{2}$. As can be observed the highest percentage loss comes from the kinetic overpotential, contributing to more than $70 \%$ of the losses. The mass transport overpotential represents a low percentage (4\%) of the losses as long as the $\mathrm{SDE}$ is run at high pressures. If the SDE were to be run at low or no pressure, the mass transport overpotential will become significant (> 20\%), severe impacting the overall performance. Ohmic losses using a $\mathrm{Nafion}^{\circledR}$ membrane can be controlled by the water content in the membrane. As long the membrane is kept at no more than $30 \mathrm{wt} \%$ acid, the contributions are relatively low $(<20 \%)$.

Table 1 Contribution of overpotential terms for MEA \#8 at a current density of 500 $\mathrm{mA} / \mathbf{c m}^{2}$

\begin{tabular}{|c|c|c|}
\hline Pressure (atm) & $\begin{array}{c}\text { Overpotential } \\
\text { Kinetic/Ohmic/Mass } \\
(\mathrm{V})\end{array}$ & $\begin{array}{c}\text { Contribution Percentage } \\
\text { Kinetic/Ohmic/Mass } \\
(\%)\end{array}$ \\
\hline 2 & $0.562 / 0.075 / 0.124$ & $74 / 10 / 16$ \\
\hline 3 & $0.544 / 0.095 / 0.0554$ & $78 / 14 / 8$ \\
\hline 4 & $0.553 / 0.105 / 0.028$ & $81 / 15 / 4$ \\
\hline
\end{tabular}


These results indicate that increasing the activity of the anode catalyst offers the greatest opportunity to improve performance to attain the SDE goal of $0.6 \mathrm{~V}$ at $500 \mathrm{~mA} / \mathrm{cm}^{2}$. There are several ways of accomplishing the reduction of the kinetic overpotential; these include increasing the catalyst surface area, using alternative catalysts with better $\mathrm{SO}_{2}$ kinetics, increasing the porosity and loading of the catalyst. During this work the focus was placed on studying alternative catalyst materials in specific bimetallic platinum catalysts.

\subsection{CONCLUSIONS AND RECOMMENDATIONS}

Fiscal year 2008 studies in electrolyzer component development have focused on the postmortem characterization of membrane electrode assemblies (MEA) from single cell electrolyzer testing, evaluation of electrocatalysts and membranes using a small scale electrolyzer and evaluating the contribution of individual cell components to the overall electrochemical performance.

Scanning electron microscopic (SEM) studies of samples taken from MEAs tested in the SRNL single cell electrolyzer test station indicates a sulfur-rich layer forms between the cathode catalyst layer and the membrane. Based on a review of operating conditions for each of the MEAs evaluated, we conclude that the formation of the layer results from the reduction of sulfur dioxide as it passes through the MEA and reaches the catalyst at the cathode-membrane interface. Furthermore we believe that operating the electrolyzer at elevated pressure significantly increases the rate of formation due to increased adsorption of hydrogen on the internal catalyst surface. Thus, identification of a membrane that exhibits much lower transport of sulfur dioxide is needed to reduce the quantity of sulfur dioxide that reaches the cathode catalyst and is reduced to produce the sulfur-rich layer. Three candidate membranes are currently being evaluated that have shown promise from preliminary studies, (1) modified Nafion ${ }^{\circledR}$, (2) polybenzimadazole (PBI), and (3) sulfonated Diels Alder polyphenylene (SDAPP).

Testing examined the activity for the sulfur dioxide oxidation of platinum (Pt) and platinumalloy catalysts in $30 \mathrm{wt} \%$ sulfuric acid solution. Linear sweep voltammetry showed an increase in activity when catalysts in which Pt is alloyed with non-noble transition metals such as cobalt and chromium. However when Pt is alloyed with noble metals, such as iridium or ruthenium, the kinetic activity decreases. We recommend further testing to determine if these binary alloys will provide the increased reaction kinetic needed to meet the targets. We also plan to test the performance of these catalyst materials for both proton and sulfur dioxide reduction. The latter may provide another parameter by which we can control the reduction of sulfur dioxide upon transport to the cathode catalyst surface.

A small scale electrolyzer $\left(2 \mathrm{~cm}^{2}\right)$ has been fabricated and successfully installed as an additional tool to evaluate the effect of different operating conditions on electrolyzer and MEA performance. Currently this electrolyzer is limited to testing at temperatures up to 80 ${ }^{\circ} \mathrm{C}$ and at atmospheric pressure. 
Selected electrochemical performance data from the single cell sulfur dioxide depolarized electrolyzer were analyzed with the aid of an empirical equation which takes into account the overpotential of each of the components. By using the empirical equation, the performance data was broken down into its components and a comparison of the potential losses was made. The results indicated that for the testing conditions of $80^{\circ} \mathrm{C}$ and $30 \mathrm{wt} \%$ sulfuric acid, the major overpotential contribution ( $\sim 70 \%$ of all losses) arise from the slow reaction rate of oxidation of sulfur dioxide. The results indicate that in order to meet the target of hydrogen production at $0.5 \mathrm{~A} / \mathrm{cm}^{2}$ at $0.6 \mathrm{~V}$ and $50 \mathrm{wt} \%$ acid, identification of a better catalyst for sulfur dioxide oxidation will provide the largest gain in electrolyzer performance. 


\subsection{REFERENCES}

[1] J. Udagawa, P. Aguiar and N.P. Brandon, Journal of Power Sources, 166, 127 (2007).

[2] J.E. Funk, International Journal of Hydrogen Energy, 26, 185 (2001).

[3] D.D. Wagman, W. H. Evans, V. B. Parker, R. H. Schumm, I. Halow, S. M. Bailey, K. L. Churney, and R. L. Nuttall, J. Phys. Chem. Ref. Data, 11, 1 (1982).

[4] Westinghouse Electric Corporation, “A Study on the Electrolysis of Sulfur Dioxide and Water for the Sulfur Cycle Hydrogen Production Process”, AESD-TME-3043, July 1980.

[5] J. L. Steimke and T. J. Steeper, “Characterization Testing of $\mathrm{H}_{2} \mathrm{O}-\mathrm{SO}_{2}$ Electrolyzer at Ambient Pressure”, Westinghouse Savannah River Company, Technical Report WSRC-TR2005-00310, August 1, 2005.

[6] J. L. Steimke and T. J. Steeper, “Characterization Testing and Analysis of Single Cell $\mathrm{SO}_{2}$ Depolarized Electrolyzer”, Washington Savannah River Company, Technical Report WSRC-STI-2006-00120, September 15, 2006.

[7] P. Sivasubramanian, R. P. Ramasamy, F. J. Freire, C. E. Holland, and J. W. Weidner, International Journal of Hydrogen Energy, 32, 463 (2007).

[8] J. Stumper, H. Haas, and A. Granados, J. of the Electrochem. Society, 152, A837 (2005)

[9] Internal communication from Maximilian Gorensek, December 18, 2007 